\title{
Matthias Maetschke
}

\section{»Verdammung der Missethäter zur Bergarbeit«}

Das Scheitern der Bergwerksstrafe im frühneuzeitlichen Europa

[Condemning Convicts to the Mines. How Condemnation to the Mines Failed in Early Modern Europe.]

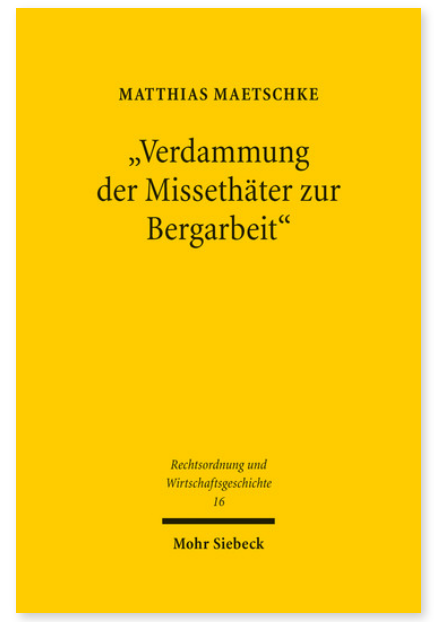

2016. XII, 309 pages. ROWG 16

ISBN 978-3-16-154284-8

cloth $79,00 €$

ISBN 978-3-16-160621-2

eBook PDF $79,00 €$
Published in German.

Ancient Roman law's punishment of sending convicts to work in mines was well-known in early modern Europe. Many held it to be a particularly fitting method of punishment. Nevertheless, all attempts to put it into practice failed. Matthias Maetschke examines the reasons why.

Matthias Maetschke Geboren 1976; Studium der Rechtswissenschaften an den Universitäten Frankfurt/Main und Bonn; 2006 Promotion; 2008 Zweites juristisches Staatsexamen; Rechtsanwalt im Bereich des privaten Immobilienwirtschaftsrechts in Düsseldorf; seit 2009 Akademischer Rat auf Zeit am Institut für Deutsche und Rheinische Rechtsgeschichte der Universität Bonn; 2015 Erteilung der venia legendi für Bürgerliches Recht, Deutsche Rechtsgeschichte und Historische Rechtsvergleichung.

\section{Order now:}

https://www.mohrsiebeck.com/en/book/verdammung-der-missethaeter-zur-bergarbeit-9783161542848?no_cache=1 order@mohrsiebeck.com

Phone: +49 (0)7071-923-17

Fax: +49 (0)7071-51104 